This item was submitted to Loughborough's Research Repository by the author.

Items in Figshare are protected by copyright, with all rights reserved, unless otherwise indicated.

\title{
People, personal data and the built environment
}

PLEASE CITE THE PUBLISHED VERSION

https://doi.org/10.1145/3064857.3064864

PUBLISHER

ACM $\odot$ The Authors

VERSION

AM (Accepted Manuscript)

\section{PUBLISHER STATEMENT}

This work is made available according to the conditions of the Creative Commons Attribution-NonCommercialNoDerivatives 4.0 International (CC BY-NC-ND 4.0) licence. Full details of this licence are available at: https://creativecommons.org/licenses/by-nc-nd/4.0/

\section{LICENCE}

CC BY-NC-ND 4.0

\section{REPOSITORY RECORD}

Schnadelbach, Holger, Nils Jaeger, Sara Nabil, Nick Dalton, David Kirk, and Elizabeth Churchill. 2019. "People, Personal Data and the Built Environment". figshare. https://hdl.handle.net/2134/32241. 


\section{People, Personal Data and the Built Environment}

$\begin{array}{ll}\begin{array}{l}\text { Holger Schnädelbach } \\ \text { Nils Jäger }\end{array} & \begin{array}{l}\text { Nick Dalton } \\ \text { David Kirk } \\ \text { Mixed Reality Lab }\end{array} \\ \begin{array}{l}\text { NorSC, } \\ \text { Nomputer Science }\end{array} & \begin{array}{l}\text { Northumbria University, } \\ \text { Nniversity of Nottingham }\end{array} \\ \begin{array}{l}\text { Nottingham, UK } \\ \text { nolger.schnadelbalton; } \\ \text { nils.jaeger@ }\end{array} & \text { david.kirk@northumbria.ac.uk } \\ \text { nottingham.ac.uk } & \text { Elizabeth Churchill } \\ & \text { Google Mountain View } \\ \text { Sara Nabil } & \text { 1600 Amphitheatre Parkway } \\ \text { Open Lab } & \text { Mountain View, CA 94043 } \\ \text { Newcastle University } & \text { churchill@acm.org } \\ \text { Newcastle upon Tyne, UK } & \\ \text { s.nabil-ahmed2@newcastle.ac.uk } & \end{array}$

Permission to make digital or hard copies of part or all of this work for personal or classroom use is granted without fee provided that copies are not made or distributed for profit or commercial advantage and that copies bear this notice and the full citation on the first page. Copyrights for third-party components of this work must be honored. For all other

uses, contact the Owner/Author.
Copyright is held by the owner/author(s). DIS'17 Companion, June 10-

14, 2017, Edinburgh, United Kingdom ACM 978-1-4503-4991-8/17/06. http://dx.doi.org/10.1145/3064857.3064864

\begin{abstract}
Personal data is increasingly important in our lives. We use personal data to quantify our behaviour, through health apps or for 'personal branding' and we are also increasingly forced to part with our data to access

services. With a proliferation of embedded sensors, the built environment is playing a key role in this

developing use of data, even though this remains relatively hidden. Buildings are sites for the capture of personal data, such as ID card gateways or wifi hotspots. This data is used to adapt buildings to people's behaviour, and increasingly, organisations use this data to understand how buildings are occupied and how communities develop. This workshop will bring together a community of researchers and practitioners interested in personal informatics and the design of interactive buildings and environments to foster critical discussion on the future role of personal data in interactions with the built environment.
\end{abstract}

\section{Author Keywords}

Personal Data; Interaction; Built Environment; Architecture; Personal Informatics

\section{ACM Classification Keywords}

H.5.0 [Information Interfaces And Presentation]:

General 


\section{Background}

Our built environment has been instrumented with sensors, actuators and computation for more than half a century [1], inspired by Weiser's vision of Ubiquitous Computing for around half of that time [2]. The resulting and still developing field of Adaptive Architecture [3] is concerned with how we specifically design buildings that respond to their environments [4] and their inhabitants [5], and this has been mapped comprehensively at adaptivearchitectureframework.org. Equally, there has been extensive research which has considered the rise of 'Personal Informatics' as we increasingly quantify our lives, our bodies and our interactions [6].

Today, Pervasive Computing spans all scales of our environment, from wearables, the smart home to the smart city. Smart homes have been explored extensively in the mid nineties, when excitement over the emerging technical possibilities was quickly tempered by the implemented realities [7]. In parallel, 'Urban computing' and 'urban informatics' have grown to become well-researched topics and the 'Smart City' [8] continues to capture the public imagination, and it is developed into real-world instantiations that people are beginning to live with. Beyond these more commonly known areas, there is also significant experimentation in research labs and design and architecture schools, developing Adaptive Architecture [9] [10]. Prototyping work emerging from research challenges our perception of the nature of the built environment, realising buildings not just as passive places but as interaction partners [11-13].
Sensors, actuators, systems

Whether more mundane and commonly encountered in the smart home, through IoT deployments and the smart city, or whether more experimental and futuristic, both types of Adaptive Architecture frequently share the principles of their basic infrastructures: sets of sensors are deployed to measure data about the environment and the inhabitants. Some software infrastructure is used to process that data and pass this on to a set of actuators in buildings. This same broad strategy allows places, for example, to for example respond to different user requirements (e.g. adapt layout) and to environmental conditions (e.g. open windows when $\mathrm{CO} 2$ levels are too high). A feedback loop emerges that links peoples' behaviours and the behaviours of adaptive environments.

\section{Built environments and personal data}

Using such infrastructure of sensors, actuators and systems, adaptive environments increasingly rely on the use of personal data to drive the desired adaptivity. It is important to adopt a broad definition of personal data as this refers to data '... which relate to a living individual who can be identified - (a) from those data, or (b) from those data and other information which is in the possession of, or is likely to come into the possession of, the data controller, and includes any expression of opinion about the individual and any indication of the intentions of the data controller or any other person in respect of the individual.', as for example defined in the UK data protection act.

The built environment includes sensors that are capable of recording personal data directly, such as ID card readers to open doors, and CCTV systems, but also 
physiological sensors [14]. Inhabitants increasingly deploy their own IoT infrastructures, including Smart TVs tracking viewing behaviours and security cameras, to mention two examples. Buildings are also the sites for sensors that record data that can become personal when combined with other sources, such as motion sensors for adaptive lighting or motion trackers (e.g. Kinect) as deployed in recent prototypes. Generally, personal data sensing has been embedded in the built environment more broadly, for example tracking people's vehicle movements, energy consumption and network access. In this way, the built environment becomes the site of the acquisition and actuation infrastructure and a key interface to personal data.

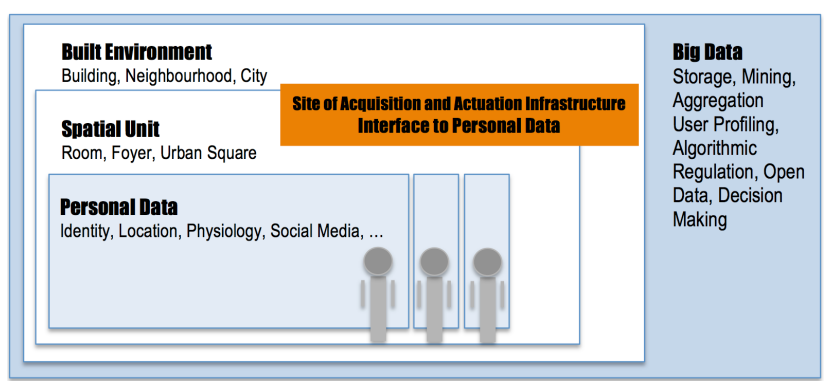

Figure 1: The built environment (at different scales) as the site of the acquisition and actuation infrastructure and as the interface to personal data.

In addition to the above infrastructure, people also actively contribute to the layering of further data, for example by broadcasting their location-tagged behaviours on social media or by posting fitness data into the cloud, to allow the build up of comprehensive pictures of specific suburbs. In this way, if not knowingly, inhabitants, organisations and the built environment 'collaborate' to create extensive data sets of personal data.

\section{People, Personal Data and the Built \\ Environment}

The described relationship of people, personal data and built environments remains poorly understood, despite it being a growing aspect of our lives. The framing proposed here will allow the contexts of IoT and the Quantified Self to be addressed in a novel way: What relationship do personal data and the built environment have? What are the needs of various stakeholders (e.g. inhabitants, facility managers, designers, builders)? How can privacy and security of personal data be supported in a shared an open spatial context? What uses for personal data are there in adaptive built environments and what are the effects of those uses?

\section{Topics and Goals}

This workshop addresses the challenges and opportunities of the specific ways in which personal data is captured, stored and made use of through the built environment. It seeks to open up and assemble innovative work on the subject and it will bring together researchers and designers from a variety of fields, who are interested in investigating the overlap of digital technologies and spatial settings, with a focus on personal data. This will include experts in $\mathrm{HCI}$,

Architecture, Urban Planning, Computing and the Social Sciences, among others.

The goal is to provide a forum for the exchange of theoretical reflections, technical approaches, built examples and in-depth studies of work that is relevant to the intersection of people, adaptive built environments and personal data, via the contributed 
paper submissions. The workshop will focus on practically addressing the topic via collaborative analysis, design and rapid paper prototyping work around a chosen and familiar context. We are looking for contributions, reflecting this under-investigated area. Themes include but are not limited to:

- Internet of Things

- Quantified self

- Adaptive Environments

- Technological retrofitting existing buildings

- Social Computing in the community

- Autonomous vehicles

- Automated delivery

- Shared digital and physical resources

- $\quad$ Living and working in the digital age

- Legible and accessible uses of personal data

- Privacy in a shared spatial context

- Design processes and BIM

- Open Data Access

- Community living and digital technology

\section{Acknowledgements}

This workshop is supported by EPSRC grant EP/N005848/2 and The University of Nottingham (Nottingham Research Fellowship).

\section{References}

1. Banham, R., The architecture of the well-tempered environment. 1969, Chicago: University of Chicago Press. 295 p.

2. Weiser, M., The Computer for the Twenty-First Century. Scientific American, 1991. 265(3): p. 94104.

3. Schnädelbach, H., Adaptive Architecture - A Conceptual Framework, in MediaCity, J. Geelhaar, et al., Editors. 2010, Bauhaus-Universität Weimar: Weimar, Germany. p. 523-555.

4. Roaf, S., M. Fuentes, and S. Thomas, EcoHouse: $A$ Design Guide. 3rd ed. 2007, Oxford: Architectural Press.

5. Chan, M., et al., A review of smart homes - Present state and future challenges. Computer Methods and Programs in Biomedicine, 2008. 91(1): p. 55-81.

6. Lupton, D., The quantified self: a sociology of selftracking. 2016, Cambridge, UK: Polity. viii, 183 pages.

7. Harper, R., Inside the smart home. 2003, London . New York: Springer. xi, 264 p.

8. Shepard, M., Sentient city : ubiquitous computing, architecture, and the future of urban space. 2011 Cambridge, USA: MIT Press. 229 p.

9. Fox, M.A. and M. Kemp, Interactive architecture. 2009, New York: Princeton Architectural Press. 256 p.

10. Bullivant, L., ed. 4dspace: Interactive Architecture. Architectural Design. 2005, Wiley-Academy. 128

11. Thomsen, M.R., Robotic Membranes - Exploring a Textile Architecture of Behaviour, in Protoarchitecture - Analogue and Digital Hybrids. 2008, John Wiley \& Sons: London. p. 92-97.

12. Beesley, P. and O. Khan, Responsive Architecture / Performing Instruments. Situated Technologies Pamphlets, 2009. 2(4).

13. Schnädelbach, H., K. Glover, and A. Irune, ExoBuilding - Breathing Life into Architecture, in NordiCHI. 2010, ACM Press: Reykjavik, Iceland. p. 442-451.

14. Schnädelbach, H., et al., ExoBuilding: Physiologically Driven Adaptive Architecture. ACM Transactions in Computer Human Interaction (TOCHI), 2012. 19(4): p. 1-22. 